\title{
Prevalence and Factors Associated with Alcohol Consumption in Urban Schools in Burkina Faso
}

\author{
Mâli Koura1, Ivlabehire Bertrand Méda², Zanga Damien Ouattara ${ }^{3}$, \\ Couna Christiane Béré Somé4, Kounpilélimé Sosthène Somda ${ }^{4}$, Aboubacar Coulibaly4, \\ Smaïla Ouédraogo ${ }^{5}$, Appolinaire Sawadogo ${ }^{1}$
}

\author{
${ }^{1}$ Hepato-Gastroenterology Unit CHU-SS, Bobo-Dioulasso, Burkina Faso \\ ${ }^{2}$ IRSS/CNRST, Ouagadougou, Burkina Faso \\ ${ }^{3}$ Hepato-Gastroenterology Unit CHU, Ouahigouya, Burkina Faso \\ ${ }^{4}$ Hepato-Gastroenterology Unit CHU-YO, Ouagadougou, Burkina Faso \\ ${ }^{5}$ Public Health Department CHU-YO, Ouagadougou, Burkina Faso \\ Email:damzang@yahoo.com
}

How to cite this paper: Koura, M., Méda, I.B., Ouattara, Z.D., Somé, C.C.B., Somda, K.S., Coulibaly, A., Ouédraogo, S. and Sawadogo, A. (2017) Prevalence and Factors Associated with Alcohol Consumption in Urban Schools in Burkina Faso. Open Journal of Gastroenterology, 7, 187-196. https://doi.org/10.4236/ojgas.2017.76020

Received: April 1, 2017

Accepted: June 27, 2017

Published: June 30, 2017

Copyright ( 2017 by authors and Scientific Research Publishing Inc. This work is licensed under the Creative Commons Attribution International License (CC BY 4.0).

http://creativecommons.org/licenses/by/4.0/

\begin{abstract}
Background: In 2005, the World Health Assembly asked member states to develop effective strategies and programs to reduce the negative consequences of harmful use of alcohol. To develop effective policies, we must already understand the phenomenon of alcohol consumption. But in Francophone west Africa, there are very few studies on the prevalence of alcohol, consumption patterns and factors associated with this consumption. The objectives of this study were to estimate the prevalence of alcohol use in schools in Burkina Faso and to identify socio-demographic factors associated with episodes of "heavy drinking". Method: A cross-sectional study was conducted in October 2013 in six secondary schools of Bobo-Dioulasso. Three hundred and sixty-two students randomly drawn by stratified cluster sampling were interviewed by using a self-administered questionnaire adapted from the model ESPAD and WHO AUDIT questionnaire. HED (Heavy Episodic Drinking) was defined as consuming at least six local measures of alcoholic beverages around the 30 days prior investigation. The search for factors was performed using logistic regression and estimating standard errors were adjusted for clustering data. Results: The prevalence of experimentation of alcohol was estimated to $45.6 \%$ [CI 95\% $=40.4-50.7]$. This prevalence was reduced to $34.8 \%$ [CI 95\% $=29.9-39.7$ ], 24.3\% [CI 95\% $=19.9-28.7$ ] and $18 \%$ [CI 95\% $=$ 14 - 21.9] if one considered the use of alcohol at least once respectively in the 12 months, 30 days and 7 days before the survey. The prevalence of HED was $16 \%$ [CI95\% $=12.2-19.8]$. Independent factors associated with the HED were alcohol use by parents or friends and father's occupation. Episodes of "heavy drinking" were $8.3(\mathrm{CI} 95 \%=4.9-14)$ and $2.8(\mathrm{CI} 95 \%=1.3-5.8)$ respec-
\end{abstract}


tively more frequent among students whose parents and friends were drinking. Neither religion nor sex nor age was not statistically associated with HED.

Conclusion: This study confirms the high prevalence of alcohol consumption in schools in Burkina Faso and challenges policy makers to adopt effective policies to fight against the harmful use of alcohol especially in schools.

\section{Keywords}

Prevalence, Heavy Drinking, School, Associated Factors

\section{Introduction}

In 2012, 3.3 million deaths and $5.1 \%$ of the global burden of disease were attributable to alcohol consumption according to the World Health Organization (WHO) [1]. Alcohol is associated with over 200 diseases including liver cirrhosis, pancreatitis, cancers, diabetes, intentional and unintentional injury, etc. [2] [3]. The use of alcohol would also increase the risk of infection with certain infectious diseases such as HIV and tuberculosis [4] [5]. Children and adolescents are more vulnerable since the initiation to alcohol is early and the risk of dependence and abuse in adulthood is high. In addition, in the case of school youth, alcohol consumption can lead to school dropout.

The use of alcohol may not only affect health but the way we drink also counts. This defines Heavy Episodic Drinking (HED) as the consumption of 60 grams or more of pure alcohol (6 or more standard measures in most countries) on one occasion during the last 30 days [1]. People classified in the category HED constitute a risk group even if their alcohol consumption is usually low because episodes of heavy drinking exposed to violence, injury, poisoning [1].

If there is generally in developed countries, laws governing the sale of alcohol by prohibiting its sale including generally the age of 18 , it is not the same in developing countries, including Africa. Alcohol is generally sold without any age restriction. In 2012, the proportion of countries which had a policy on alcohol ranged from $20 \%$ in the WHO African region to $64 \%$ in the WHO Europe zone [1]. Worse, in some societies, alcohol is a key element of social activities (funerals, weddings, etc.) and its consumption by the youngest is widely accepted. This is the case in the majority of Burkina Faso's ethnic groups.

The Fifty-eighth World Health Assembly asked in 2005 to Member States to develop effective strategies and programs to reduce the negative consequences of harmful use of alcohol [6]. However, to develop effective programs, we must already know each other concerned groups and the factors associated with the use of alcohol. But one still knows about the prevalence of alcohol consumption and factors associated with consumption in West Africa Francophone. A study published in 2010 in four countries (Ghana, Burkina Faso, Uganda, Malawi) reported that $4.3 \%$ of Burkinabe 12 - 19 years old (5.3\% of boys and $3.1 \%$ girls) consumed alcohol 12 months before the survey [7]. The age, sex, marital status 
and the student status were factors associated with alcohol consumption. A survey conducted earlier in 2006 , at school, indicated that $34.4 \%$ of students had consumed alcohol at least once in their lives [8]. Alcohol consumption in the family circle or friends was the factor associated with the use of alcohol among students. In Ivory Coast, a study was also conducted in urban schools in 2011 [9]. It was reported that $36.1 \%$ of students had consumed alcohol and religion, the consumption of alcohol by parents were among other determinants of alcohol use among students. In Benin, a survey conducted 2014 showed that $30.1 \%$ of people 10 to 19 years had consumed alcohol [10]. Age, marital status, place of residence and the consumption of alcohol by neighbors were found as predictors of the use of alcohol among young people.

Our study contributes to the reinforcement of a very fragmented literature on alcohol use in West Africa Francophone. Its objectives were to estimate the prevalence of alcohol consumption in schools in Bobo-Dioulasso and to identify sociodemographic factors associated with consumption.

\section{Methods}

\subsection{Study Setting}

Bobo-Dioulasso is the second city of Burkina Faso. It covers an area of 136.78 $\mathrm{km}^{2}$ and is located to $365 \mathrm{~km}$ from the capital Ouagadougou. Its population was estimated to 813,610 inhabitants in the year 2012 [11]. The main ethnic groups are the Dioula, Mossi and Bobo [11]. The predominant religion is Islam, practiced by $76.7 \%$ of the population against $19.0 \%$ for Catholics and $3.0 \%$ for Protestants [11]. The city has 118 high schools in October 2013 in which 10 public and 108 private.

\subsection{Study Design, Population and Sampling}

This was a cross-study in October 2013. The study population consisted of students of class $4^{\text {th }}, 3^{\text {rd }}, 2$ nd and lere (respectively $9^{\text {th }}, 10^{\text {th }}, 11^{\text {th }}$ and $12^{\text {th }}$ years of schooling) from high schools, public and private secondary schools in Bobo-

Dioulasso. The choice of these classes was guided by the concern to obtain an especially adolescent population and who can easily understand the questionnaire.

Sampling was stratified cluster. The clusters were formed by educational institutions. They were first stratified by geographic location (East, West, South, Central and North). A school was then randomly drawn from each stratum except the central one where both institutions have been fired because of the greater number of schools and colleges for this geographical location.

The sample size was calculated for a simple random sampling using a $95 \%$ confidence level, a 5\% margin of error and an expected prevalence of $34 \%$ for those who have already experienced alcohol (prevalence coming from the study of Nikiema et al.). This gave a sample of 345 students. This size was increased by $10 \%$ to take account the refusal to answer or incomplete responses which finally gave a size of 380 students. Each selected high school or college, we randomly 
drew 16 students in each of four classes.

\subsection{Data Source and Collection}

The data were collected using a self-administered questionnaire. The questionnaire was adapted to the model of the ESPAD (European School Survey Project on Alcohol and other Drugs) and the AUDIT Questionnaire (Alcohol Use Disorders Identification Test) WHO to reflect the vocabulary of students and denominations of some local alcohols. We defined the experimentation as the consumption of alcohol at least once in the life of the individual whether he continued this consumption later or not [12]. HED was defined as the consumption of 6 bottles of beer or more, 6 liters of dolo or more, 6 or more glasses of wine or 6 balls of liquor or more on a single occasion at least once in the 30 days preceding the survey. Students were asked about their consumption of alcohol at least once in life, in the last 12 months, the last 30 days and the seven days preceding the survey. For the consumption of the 30 and last week, the amount consumed was collected.

Other variables indicated concerned the socio-demographic characteristics of the students and their parents (age, sex, marital status of parents, family environment, parents' religion, and parental occupation), consumption of alcohol in the family circle or the friends consumed alcohol type, quantity consumed, age at first use, the use of cigarettes.

Data collection was performed by a physician trained for this purpose. In each school selected students were gathered in a room to complete the questionnaire.

\subsection{Ethical Aspects}

The study received approval from the DRESS (Regional Directorate of Secondary and Higher Education) of the Hauts-Bassins. The selected students have given written consent and questionnaires were anonymous. The analysis does not recognize the institutions concerned.

\subsection{Data Entry and Analysis}

Data were entered using the EPI Data software and analyzed with Stata April 1.0. The prevalence was calculated for the different periods by dividing the number of consumers over the period by the size of the sample. For research, factors associated with HED related to students, we used multiple logistic regression. The dependent variable was HED and was 1 for all those who had had at least one HED within 30 days preceding the survey, and 0 if not. A bivariate analysis using the Chi-2 test was first performed. All variables that were associated with $p<0.25$ [13] in bivariate analysis were included in the multiple logistic regression using stepwise method. Standard errors were adjusted for the data cluster at school. The wald test was used to compare nested models. The adequacy of the model was verified by a graphic inspection of the tailings. Odds crude and adjusted ratio and $95 \%$ confidence intervals were calculated for the variables included in the multiple logistic regression. A threshold $\alpha$ equal to 0.05 was considered for sta- 
tistical significance.

\section{Results}

\subsection{Sample Description}

A total of 362 students completed questionnaires corresponding to a rate of response which is $94.3 \%$. The sample consisted of $57.2 \%$ male. The average age was $17.8 \pm 2.4$ years old with extremes of 13 and 25 years. Islam was practiced by the parents of students at $68 \%$. The majority $(68 \%)$ of the students said that both their parents lived together in the same house; $13.8 \%$ said that their two parents were separated or divorced and $18.0 \%$ of the students were orphans of at least one parent. Table 1 presents the socio-demographic characteristics of the students in our sample.

\subsection{Prevalence of Alcohol Consumption}

The prevalence of alcohol use at least once in life was 45.6\% [CI 95\% $=40.4$ 50.7]. This prevalence was reduced to $34.8 \%$ [CI $95 \%=29.9-39.7$ ], $24.3 \%$ [CI $95 \%=19.9-28.7$ ] and 18\% [CI 95\% = $14-21.9$ ] if one considered the use of alcohol at least once in the 12 months respectively, 30 days and 7 days before the survey. The average age for initiation to alcohol was $12.6 \pm 4.2$ years, ranging from 4 to 21 years.

In the 7 days preceding the survey, 36, 34, 32 and 11 students (out of the 65 who consumed alcohol) consumed respectively beer, dolo, wine and liquor. The quantities consumed by student on average $2.6 \pm 2.3$ bottles of beer $(66 \mathrm{cl}=1$ bottle), $2.3 \pm 1.2$ glasses of wine, 1.7 liters of dolo \pm 1.6 and $1.8 \pm 1.8$ liqueur balls.

Within 30 days preceding the survey, $16 \%$ of students [CI $95 \%=12.2-19.8$ ] consumed once at least more than six drinks on one occasion and were therefore classified as HED category.

\subsection{Sociodemographic Factors Associated with Episodes of Heavy Drinking}

In bivariate analysis, episodes of Heavy drinking were 3.6 times more frequent [CI 95\% (2.0 - 6.3)] among students whose parents were not Muslim, compared to those whose parents were Muslims. The episodes of Heavy drinking also were $10.7(\mathrm{CI} 95 \%=5.5-20.9)$ and 4.2 times (CI 95\% $=2.2-8.1)$ respectively more frequent among students with at least one parent and friends drinking compared to those whose parents or friends do not drink.

In multiple logistic regression, only alcohol consumption by parents and friends as well as the father's occupation were factors associated with Heavy drinking episodes among students. Thus, compared to farmers, HED is 2.7 times more common among students whose parents are employees. The frequencies of HED with students with at least one parent and friends consuming alcohol were reduced but remained statistically significant at respectively 8.3 (CI 95\% $=4.9$ 14) and 2.8 (CI 95\% = $1.3-5.8)$. Table 2 presents the adjusted odds ratio, not adjusted for factors associated with episodes of heavy drinking. 
Table 1. Socio-demographic characteristics of secondary school students in Bobo-Dioulasso in 2013 according to whether they are classified HED or not.

\begin{tabular}{|c|c|c|c|c|c|}
\hline \multirow{2}{*}{ Variables $(n=362)$} & \multicolumn{2}{|c|}{ Numbers } & \multicolumn{2}{|c|}{ Percentages } & \multirow{2}{*}{$\mathbf{P}$} \\
\hline & HED & No HED & HED & No HED & \\
\hline \multicolumn{6}{|l|}{ Ethnicity } \\
\hline - mossi & 15 & 121 & 11.0 & 89.0 & \multirow{7}{*}{0463} \\
\hline - Bobo/Dioula & 15 & 60 & 20.0 & 80.0 & \\
\hline - Senoufo/Toussian & 7 & 31 & 18.4 & 81.6 & \\
\hline - Gourounsi & 5 & 15 & 25.0 & 75.0 & \\
\hline - Fulani/Fulse & 3 & 15 & 16.7 & 83.3 & \\
\hline - Samo & 3 & 22 & 12.0 & 88.0 & \\
\hline - Other & 10 & 40 & 20.0 & 80.0 & \\
\hline \multicolumn{6}{|l|}{ Sex } \\
\hline - Male & 34 & 173 & 16.4 & 83.6 & \multirow[t]{2}{*}{0809} \\
\hline - Female & 24 & 131 & 15.5 & 84.5 & \\
\hline \multicolumn{6}{|l|}{ Parent's religion } \\
\hline - Muslim & 25 & 222 & 10.1 & 89.9 & \multirow[t]{2}{*}{$<0.001$} \\
\hline - Other & 33 & 82 & 28.7 & 71.3 & \\
\hline \multicolumn{6}{|l|}{ Father's education } \\
\hline - No education & 16 & 117 & 12.0 & 88.0 & \multirow{4}{*}{0138} \\
\hline - Primary & 7 & 45 & 13.5 & 86.5 & \\
\hline - Secondary or more & 24 & 81 & 22.9 & 77.1 & \\
\hline - Other* & 11 & 61 & 15.3 & 84.7 & \\
\hline \multicolumn{6}{|l|}{ Mother's education } \\
\hline - No education & 25 & 154 & 14.0 & 86.0 & \multirow{4}{*}{0053} \\
\hline - Primary & 9 & 62 & 12.7 & 87.3 & \\
\hline - Secondary or more & 19 & 52 & 26.8 & 73.2 & \\
\hline - Other* & 5 & 36 & 12.2 & 87.8 & \\
\hline \multicolumn{6}{|l|}{ Parent's marital status } \\
\hline - Married & 41 & 205 & 16.7 & 83.3 & \multirow{3}{*}{0642} \\
\hline - Separated/divorced & 9 & 41 & 18.0 & 82.0 & \\
\hline - Widowers & 8 & 57 & 12.3 & 87.7 & \\
\hline \multicolumn{6}{|l|}{ Social environment } \\
\hline - With father and mother & 39 & 167 & 18.9 & 81.1 & \multirow{3}{*}{0207} \\
\hline - With father or mother & 9 & 58 & 13.4 & 86.6 & \\
\hline - Other Parent & 10 & 79 & 11.2 & 88.8 & \\
\hline \multicolumn{6}{|l|}{ Parent's consumer } \\
\hline - No & 15 & 223 & 6.3 & 93.7 & \multirow{3}{*}{$<0.001$} \\
\hline - At least one parent & 36 & 50 & 41.9 & 58.1 & \\
\hline - Other ${ }^{\star}$ & 7 & 31 & 18.4 & 81.6 & \\
\hline \multicolumn{6}{|l|}{ Friend's consumer } \\
\hline - Yes & 31 & 65 & 32.3 & 67.7 & \multirow[t]{2}{*}{$<0.001$} \\
\hline - No. & 27 & 239 & 10.2 & 89.8 & \\
\hline Cigarettes & & & & & \\
\hline - Yes & 9 & 24 & 27.3 & 72.7 & 0065 \\
\hline - No. & 49 & 280 & 14.9 & 85.1 & \\
\hline Age & & & & & \\
\hline - $13-14$ years & 4 & 25 & 13.8 & 86.2 & 0213 \\
\hline - $15-17$ years & 17 & 123 & 12.1 & 87.9 & 0213 \\
\hline - $18-25$ & 37 & 156 & 19.2 & 80.8 & \\
\hline
\end{tabular}




\section{Continued}

\begin{tabular}{lccccc}
\hline Father's occupation & & & & & \\
- Farmer & 13 & 94 & 12.2 & 87.8 & \\
- trader & 12 & 93 & 11.4 & 88.6 & 0007 \\
- salaried & 25 & 66 & 27.5 & 72.5 & \\
- Other** & 8 & 51 & 13.6 & 86.4 & \\
Mother's occupation & & & & & \\
- Household & 43 & 235 & 15.5 & 84.5 & \\
- shopping & 8 & 33 & 19.5 & 80.5 & \\
- Salaried & 4 & 20 & 16.7 & 83.3 & \\
- Other* & 3 & 16 & 15.8 & 84.2 & \\
\hline
\end{tabular}

Other*: No information deceased. Other ${ }^{* *}$ : Other profession and died.

Table 2. Odds ratio unadjusted and adjusted for socio-demographic factors associated with episodes of heavy drinking among school children in Bobo-Dioulasso in 2013.

\begin{tabular}{|c|c|c|c|c|c|}
\hline \multirow{2}{*}{ Variables $(\mathrm{N}=362)$} & \multirow{2}{*}{ NOT } & \multicolumn{2}{|c|}{ Crude } & \multicolumn{2}{|c|}{ adjusted } \\
\hline & & GOLD & CI $95 \%$ & GOLD & CI $95 \%$ \\
\hline \multicolumn{6}{|l|}{ Religion } \\
\hline - Muslim & 247 & 1 & & & \\
\hline - Other & 115 & 3.6 & $2.0-6.3$ & & NS \\
\hline \multicolumn{6}{|l|}{ Father's education } \\
\hline - No education & 133 & 1 & & & \\
\hline - primary & 52 & 1.1 & $0.2-5.4$ & & \\
\hline - Secondary or more & 105 & 2.2 & $0.9-4.9$ & & NS \\
\hline - Other & 72 & 1.3 & $0.7-2.4$ & & \\
\hline \multicolumn{6}{|l|}{ Mother's education } \\
\hline - No education & 179 & 1 & & & \\
\hline - Primary & 71 & 0.9 & $0.4-1.8$ & & NS \\
\hline - Secondary or more & 71 & 2.3 & $1.5-3.4$ & & \\
\hline - Other & 41 & 0.9 & $0.3-2.7$ & & \\
\hline \multicolumn{6}{|l|}{ social environment } \\
\hline - With mother and father & 206 & 1 & & & \\
\hline - With mother or father & 67 & 0.7 & $0.4-1.1$ & & NS \\
\hline - Other Parent & 89 & 0.5 & $0.3-0.9$ & & \\
\hline \multicolumn{6}{|l|}{ Parent's consumer } \\
\hline - $\mathrm{No}$ & 238 & 1 & & 1 & \\
\hline - At least one parent & 86 & 10.7 & $5.5-20.9$ & 8.3 & $4.9-14.0$ \\
\hline - Other & 38 & 3.4 & $1.4-8.3$ & 3.4 & $1.4-8.3$ \\
\hline \multicolumn{6}{|l|}{ Friend's consumer } \\
\hline - No. & 266 & 1 & & 1 & \\
\hline - Yes & 96 & 4.2 & $2.2-8.1$ & 2.8 & $1.3-5.8$ \\
\hline \multicolumn{6}{|l|}{ Tobacco } \\
\hline - No. & 329 & 1 & & & \\
\hline - Yes & 33 & 2.1 & $0.7-6.1$ & & NS \\
\hline \multicolumn{6}{|l|}{ Student's age } \\
\hline - $13-14$ years & 29 & 0.7 & $0.2-2.8$ & & \\
\hline - $15-17$ years & 140 & 0.6 & $0.2-1.6$ & & NS \\
\hline - 18 - 25 years & 193 & 1 & & & \\
\hline \multicolumn{6}{|l|}{ Father's occupation } \\
\hline - Farmer & 107 & 1 & & 1 & \\
\hline - trader & 105 & 0.9 & $0.5-1.8$ & 1.5 & $0.7-2.9$ \\
\hline - salaried & 91 & 2.7 & $1.8-4.1$ & 1.9 & $1.4-2.5$ \\
\hline - other & 59 & 1.1 & $0.4-2.9$ & 0.9 & $0.4-2.1$ \\
\hline
\end{tabular}




\section{Discussion}

In this study, the prevalence of School drinking were $45.6 \%$ [CI 95\% $=40.4$ 50.7], 34.8\% [CI 95\% $=29.9-39.7$ ] and $24.3 \%$ [CI 95\% $=19.9-28.7$ ] respectively for experimentation, in the last 12 months and 30 days preceding the survey. The factors associated with alcohol consumption were link to parents or friends consumption and parents' occupation.

The prevalence of experimentation of alcohol in schools in Bobo Dioulasso is higher than that (34.14\%) reported 10 years earlier by Nikiema et al. in Ouagadougou [8]. A prevalence of use in the last 12 months (36.1\%) similar to ours was reported in 2011 in a secondary school in Abidjan [9], however; the authors did not specify the observation window. A prevalence twice higher $(74.6 \%)$ of consumption the last 30 days was reported in 2014 in a hospital zone of Benin [10], but this study included all young people going to school or out of school from 12 to 19 years old from urban and rural areas in a health area of Benin.

This high prevalence of alcohol consumption in schools in Burkina is in itself not a surprise. Indeed, promotional sales activities of drinks are organized in public places sometimes not far from schools and colleges or on the screens of the national television and students are exposed. To this must be added a certain cultural tolerance for alcohol in our societies. Thus, one can observe in certain regions or among certain ethnic groups in our country that parents give to drink to children under five years. This cultural influence and certain accessibility to local drinks could also explain the average age initiation to alcohol which is only 12 years old with a minimum of four years.

The prevalence of difference observed in our study with that of Nikiema et al. [8] could be explained by a worsening in the time of alcohol phenomenon in schools in Burkina. It may also reflect a regional variation in alcohol consumption in schools. Some regions such as Bobo-Dioulasso consist of ethnic groups among which the local alcohol (dolo) is an essential element of the socio-cultural life (weddings, funerals, meetings, field work, etc.).

Although the prevalence of alcohol consumption is high in schools, it can be considered as occasional since going from $45.6 \%$ for the experiment to $18 \%$ during the seven days preceding the survey.

The prevalence of HED is $16 \%$ in our study. In Benin, Kpozehouen et al. found in 2014, 30.08\% of misuse of alcohol (abusers, harmful use to consumers and alcohol-dependent). Globally, the WHO estimates the prevalence of HED to $16 \%$ [1]. This HED high prevalence shows that not only a good portion of students drink but also that a significant proportion consists of at-risk drinkers.

Independent factors associated with heavy drinking episodes were the consumption of parents and friends and the father's occupation. The religion that was statistically associated in the bivariate analysis was no longer in multivariate. The influence of alcohol consumption by family and/or friends about alcohol use was reported by several studies in Africa and is not limited only to school [8] [9] [10]. According to WHO, the use of alcohol by parents increases the risk to consumer risk in children [1]. 
In Ivory Coast, N'Cho Dagnan Simplice et al. had found that alcohol consumption was more common among students who received more than 5000 FCFA (7.62 euros) as pocket money weekly [9]. In our study, episodes of heavy drinking are more common among students whose parents are employees. Presumably they are also those students who have pocket money offering them the opportunity to afford alcohol.

Religion and gender were not independent factors associated with heavy drinking episodes in our study. Nikiema et al. (2011) did not find an association between religion, sex and the alcohol consumption among students in Ouagadougou. In contrast, in Ivory Coast, Dagnan et al. (2014) found that alcohol was more common in the Christian confession of students compared to Muslims. The adjustment was made only for socio-demographic variables in our study and it is possible that the persistence of residual confounding explains the fact that religion is not statistically associated in our study. However, Islam in Burkina seems less rigorous and it is not unusual to find alcoholic beverages in people of Muslim faith during feasts. This lack of association may reflect the reality in our context especially as Nikiema et al. (2011) did not find an association between alcohol and religion.

The calculation of the sample size did not take into account the effect and it is possible that the size used is not appropriate for efficient estimation of prevalence. Moreover, the number of students classified HED was relatively small $(n=58)$, which did not in multivariate analysis to have accurate estimations. However, this is one of the first studies in West Africa francophone that estimates the prevalence related to HED in schools and research associated factors.

\section{Conclusions}

The prevalence of alcohol consumption in schools in Bobo-Dioulasso, is high with a prevalence of experimentation estimated to $45.6 \%$ while $16 \%$ of students were classified as HED category considered by the WHO as a group at risk. This study also confirmed the influence of alcohol consumption in the family circle and friends in student behavior with respect to alcohol.

Burkina Faso has adopted a few years ago a law banning tobacco consumption in public places such as schools, hospitals, etc. But there is no similar legislation for alcohol and implementation of drinking establishments in the cities which don't take into account the proximity of schools. It is probably the time that the authorities are concerned about it and that awareness is reinforced to parents and students. Further studies should also clarify the influence of the proximity of drinking establishments with schools on student behavior towards alcohol to provide evidence to encourage public authorities to act.

\section{References}

[1] WHO (2014) Global Status Report on Alcohol and Health.

[2] Baan, R., Straif, K., Big, Y., Secretan, B., El Ghissassi, F., Bouvard, V., et al. (2007) Carcinogenicity of Alcoholic Beverages. The Lancet Oncology, 8, 292-293. https://doi.org/10.1016/S1470-2045(07)70099-2 
[3] Shield, K.D., Parry, C. and Rehm, J. (2013) Chronic Diseases and Conditions Related to Alcohol Use. Alcohol Research, 35, 155-173.

[4] Baliunas, D., Rehm, J., Irving, H. and Shuper, P. (2010) Alcohol Consumption and Risk of Incident Human Immunodeficiency Virus Infection: A Meta-Analysis. International Journal of Public Health, 55, 159-166.

https://doi.org/10.1007/s00038-009-0095-x

[5] Rehm, J., Samokhvalov, A.V., Neuman, M.G., Room, R., Parry, C., Lonnroth, K., et al. (2009) The Combination between Alcohol Use, Alcohol Use Disorders and Tuberculosis (TB): A Systematic Review. BMC Public Health, 9, 450. https://doi.org/10.1186/1471-2458-9-450

[6] WHO (2005) Public-Health Problems Caused by Harmful Use of Alcohol. http://www.who.int/substance abuse/activities/public health alcohol/en/

[7] Kabiru, C.W., Beguy, D., Crichton, J. And Ezeh, A.C. (2010) Self-Reported Drunkenness among Teenagers in Sub-Saharan African Countries Oven: Associations with Adverse Childhood Experiences. Child and Adolescent Psychiatry and Mental Health, 4, 17. https://doi.org/10.1186/1753-2000-4-17

[8] Nikiéma, L., Kouanda, S., Seck, I., Tiendrebéogo, S., Ouédraogo, H., Yaméogo, M., et al. (2011) Psychotropic Consumption in Schools in Burkina Faso. Prevalence and Risk Factors for Science and Technology. Health Sciences, 34, 65-82.

[9] N'Cho Simplice Dagnan, D., Zengbé Acray, P., Ahoussou, E.M.K., Ekou, F.K., Kouassi, D.P., shortbread, P.S., et al. (2014) Urban Alcohol Consumption among High School Students in Côte d'Ivoire.

[10] Kpozehouen, A., Ahanhanzo, Y.G., Paraïso, M.N., Munezero, F., Saizonou, J.Z., Makoutodé, M., et al. (2016) Factors Associated with Substance Use among Adolescents in Benin. Public Health, 27, 871-880.

[11] (INSD)INdlSedlD (2015) In 2014 Statistical Yearbook.

[12] Alcohology, S.F. (2001) Choice and Definition of Hand in Terms Alcohological Practice. Alcohol Addiction and Abuse, 23, 65-125.

[13] Hosmer, D.W., Lemeshow, S. and Sturdivant, R.X. (2005) Model-Building Strategies and Methods for Logistic Regression. In: Applied Logistic Regression, John Wiley \& Sons, Inc., Hoboken, 91-142. https://doi.org/10.1002/0471722146.ch4

Submit or recommend next manuscript to SCIRP and we will provide best service for you:

Accepting pre-submission inquiries through Email, Facebook, LinkedIn, Twitter, etc. A wide selection of journals (inclusive of 9 subjects, more than 200 journals)

Providing 24-hour high-quality service

User-friendly online submission system

Fair and swift peer-review system

Efficient typesetting and proofreading procedure

Display of the result of downloads and visits, as well as the number of cited articles

Maximum dissemination of your research work

Submit your manuscript at: http://papersubmission.scirp.org/

Or contact ojgas@scirp.org 